\title{
What's in a food bag? Analysis of the content of food bags provided by the Bradford Metropolitan Food Bank
}

\author{
H. Preston and V. J. Burley \\ School of Food Science \& Nutrition, University of Leeds, Leeds LS2 9JT, UK
}

Food banks in the UK provide a form of emergency food provision for individuals without the means to purchase food ${ }^{(1)}$. In the past few years there has been an unprecedented rise in the numbers of food banks being set up, and in the apparent demand for the emergency food support that they provide. The Trussell Trust, one of the largest food bank organisations in the UK recently reported that the numbers of requests for food bags had trebled in the past year, and that it provided bags to more than 350,000 people across the UK between April and September in $2013^{(2)}$. However, a recent review acknowledged the lack of information available about who accesses food banks and other emergency food aid in the UK, their reasons for doing so, and the potential impact of this aid on its recipients ${ }^{(3)}$

The Bradford Metropolitan Food Bank is an independent charitable organisation that was set up in 2004. It is completely run by volunteers from the local area that together collect and pack food items into a carrier bag for distribution to vulnerable individuals via local care professionals within the Bradford Metropolitan area. As a first step towards providing nutritional guidance to the Bradford Metropolitan Food Bank regarding the purchase of food stuffs to supplement donations from the general public, a survey of a random selection of 51 pre-packed food bags was undertaken to determine their content and nutritional composition. The food analysis software, Windiets, which is based on current UK composition of foods tables was used to analyse the nutritional content of each bag. Since the gender and age of each food bag recipient is unknown (adults only) to the bag packers, the adequacy of each food bag to meet the nutritional needs of an average adult for 3 days was assessed by comparing the nutritional composition against the Reference Intake (RI).

\begin{tabular}{|c|c|c|c|c|}
\hline Nutrient & Mean & SD & RI for 3 days & $\%$ of 3 day RI \\
\hline Energy (kj) & 53853 & 9234 & 25080 & 218 \\
\hline Protein $(\mathrm{g})$ & 288 & 52 & 150 & 192 \\
\hline Total carbohydrate (g) & 2619 & 548 & 780 & 109 \\
\hline Non milk extrinsic sugars $(\mathrm{g})$ & 1392 & 401 & 270 & 516 \\
\hline Fat $(g)$ & 189 & 72 & 210 & 90 \\
\hline Saturated Fat (g) & 67 & 27 & 60 & 112 \\
\hline Non Starch Polysaccharide (g) & 76 & 25 & 54 & 140 \\
\hline Salt $(\mathrm{g})$ & 57 & 104 & 18 & 316 \\
\hline Folate $(\mu \mathrm{g})$ & 2094 & 651 & 600 & 349 \\
\hline Iron $(\mathrm{mg})$ & 82 & 14 & 42 & 194 \\
\hline Calcium (mg) & 2961 & 664 & 2400 & 123 \\
\hline
\end{tabular}

Bag content is variable, being constrained by the nature of food donations and limitations to non-perishable items. They contained on average, 18 items. A typical food bag included a $500 \mathrm{~g}$ box of cereal, $1 \mathrm{~L}$ carton of UHT milk, 40 tea bags or a jar of coffee, a bag of sugar, a packet of biscuits, 1L of fruit squash, a tin each of soup, fruit, vegetables, baked beans, spaghetti, chickpeas or other beans and fish or meat, a jar of pasta sauce, a packet of rice or pasta, a packet of instant noodles, a packet of crisps, a cereal or chocolate bar, and a sweet or savoury jar. As a form of emergency food aid, food bags provide sufficient energy and macronutrients to meet the needs of an average adult for 3 days. There may however, be some concern about the high levels of salt and non-milk extrinsic sugars provided for individuals who are long term or repeat recipients.

1. Lambie-Mumford H. (2013). J Soc Policy 42(1), 73-89.

2. Trussell Trust. (2012). [Press Release]. Available from: http://www.trusselltrust.org/resources/documents/UK-foodbanks-double-numbers-fed-inone-year1.pdf

3. Lambie-Mumford H, Crossley D, Jensen E, et al. (2014) Household Food Security in the UK: A Review of Food Aid. Available from: https://www. gov.uk/government/uploads/system/uploads/attachment_data/file/283071/household-food-security-uk-140219.pdf 